\title{
CENTRO DIDÁTICO-PEDAGÓGICO PARA O GERENCIAMENTO INTEGRADO DE RESÍDUOS SÓLIDOS: ESTUDO DE CASO PARA AVALIAÇÃO DE VIABILIDADE NO INSTITUTO FEDERAL FLUMINENSE - CAMPUS MACAÉ, RJ-BRASIL
}

\author{
M. P. CORREA ${ }^{1}$ e J. A. F. SILVA ${ }^{2 *}$ \\ ${ }^{1}$ Prefeitura Municipal de Santa Maria Madalena \\ ${ }^{2}$ Instituto Federal Fluminense \\ jaferreirasilva@gmail.com*
}

Artigo submetido em julho/2015 e aceito em novembro/2015

DOI: $10.15628 /$ holos.2015.3032

\section{RESUMO}

O aumento da geração de resíduos sólidos surge em paralelo com o desenvolvimento econômico. Por isso, o gerenciamento dos resíduos sólidos converge para uma importância crescente, sendo fundamental a coerência ambiental, econômica e social. Nesse sentido, o Centro Didático-Pedagógico surge como alternativa para o gerenciamento dos resíduos sólidos no IFFluminense -
Campus Macaé, mas, vale considerar que também tende a promover a inclusão social, viabilizar ganhos sociais a partir da capacitação profissional de pessoas de baixa renda, em escala piloto e conferir benefícios ambientais, a partir da destinação correta dos resíduos gerados, não só para o IFFluminense - Campus Macaé, como também para o município de Macaé.

PALAVRAS-CHAVE: Resíduo Sólido, Gerenciamento Integrado, Centro Didático-Pedagógico.

\section{DIDACTIC-PEDAGOGIC CENTRE FOR THE INTEGRATED MANAGEMENT OF SOLID WASTE: CASE STUDY FOR FEASIBILITY ASSESSMENT IN THE INSTITUTO FEDERAL FLUMINENSE - CAMPUS MACAÉ, RJ-BRAZIL}

\section{ABSTRACT}

The increase in solid waste generation arises in parallel with economic development. Therefore, the solid waste management converges to a growing importance, being fundamental to environmental, economic and social coherency. In this sense, the Didactic-Pedagogic Center arises as an alternative for the management of solid waste in IFFluminense - Campus Macaé, but, it's worth
\end{abstract}

considering that it also tends to promote social inclusion, enabling social gains from the professional training lowincome people, on a pilot scale and provide environmental benefits, from the correct disposal of waste generated, not only for the IFFluminense-Campus Macaé, as well as for the city of Macaé.

KEYWORDS: Solid Waste, Management, Didactic-Pedagogic Center. 


\section{INTRODUÇÃO}

O aumento da geração de resíduos sólidos surge em paralelo com o crescimento populacional e com o desenvolvimento econômico e, caracteriza-se como um dos problemas centrais da atualidade, devido ao padrão insustentável de consumo da sociedade moderna, conforme afirmam Ferreira (2000), Lichtnow et. al. (2004) e Cen (2008), soma-se a esse fato a ausência de diretrizes eficientes para a questão dos resíduos e a escassez de recursos técnicos e financeiros, constituindo um obstáculo a ser superado para o equacionamento do problema, de acordo com Schalch et. al. (2002).

No Brasil, 125.281 mil toneladas de resíduos são coletadas diariamente, sendo $30,5 \%$ destinadas para lixões, 22,3\% para aterros controlados e 47,1\% vão para aterros sanitários, segundo a Pesquisa Nacional de Saneamento Básico do IBGE (2000). Assim, no mínimo 52,8\% dos resíduos são depositados de forma inadequada uma vez que os lixões e os aterros controlados não são as formas mais seguras de disposição final. Considerando tal situação, torna-se evidente a urgência em se adotar um sistema de manejo adequado para os resíduos sólidos urbanos, objetivando assegurar a melhoria contínua da qualidade de vida e da saúde pública de acordo com Schalch et. al. (2002).

Seguindo esse conceito, pretende-se gerar subsídios para o desenvolvimento de práticas de educação ambiental e cooperativismo, tendo como base a sustentabilidade. Portanto, faz-se necessário uma nova concepção para a gestão de resíduos sólidos, de forma a motivar a sociedade, bem como a comunidade escolar, no sentido de reduzir a produção de resíduos, aumentar a reutilização e a reciclagem e repensar valores para a preservação do meio ambiente.

Assim, o centro didático-pedagógico pode ser utilizado para desenvolvimento de ações na área ambiental, não só na questão dos resíduos urbanos, como também para inovação científica em diversas áreas, de maneira a disponibilizar, para a sociedade, estudos, pesquisas e tecnologias visando a melhoria das condições ambientais e da qualidade de vida. A amplitude das ações pode ser ainda maior, pois o objetivo do centro didático-pedagógico também é promover o desenvolvimento sustentado de comunidades; proporcionar a redução de custos da cooperativa, de maneira a maximizar seus rendimentos; facilitar o acesso às tecnologias desenvolvidas para as atividades de triagem e tratamento de resíduos e, ainda, difundir o conhecimento.

\section{REVISÃO BIBLIOGRÁFICA}

\subsection{Políticas Atuais e Base Legal}

$\mathrm{Na}$ esfera Federal, a questão dos resíduos sólidos foi inicialmente abordada pela Lei $\mathrm{n}$ 9.605/1998, que dispõe sobre as sanções penais e administrativas derivadas de condutas e atividades lesivas ao meio ambiente; na qual consta que, constitui crime ambiental, com pena de reclusão de um a cinco anos, o lançamento de resíduos sólidos, em desacordo com as exigências estabelecidas em leis ou regulamentos específicos, que ocasione danos à saúde humana, provoque a mortandade de animais ou a destruição significativa da flora.

Posteriormente, o tema referente aos resíduos sólidos foi abordado pela Lei $\mathrm{n}$ $11.445 / 2007$, que estabelece as diretrizes nacionais para o saneamento básico, na qual o manejo 
dos resíduos sólidos é classificado como serviço público de saneamento básico, devendo ser realizados de maneira adequada para a proteção da saúde pública e do meio ambiente. Vale ressaltar que, a citada lei considera que o manejo dos resíduos sólidos é composto pelas atividades de coleta; transbordo e transporte dos resíduos; triagem para fins de reúso ou reciclagem; tratamento, inclusive por compostagem e disposição final adequada. Portanto, nota-se que tais atividades visam melhorar a salubridade ambiental. Recentemente, foi publicado o Decreto $\mathrm{n}$ ㅇ 7.217/2010, que regulamenta a Lei no 11.445/2007. Tal decreto prevê que os planos de saneamento básico devem conter prescrições para o manejo dos resíduos sólidos urbanos.

Ainda no ano de 2010, foi publicada a Lei no 12.305 , que institui a política nacional de resíduos sólidos (PNRS) e, de acordo com seu artigo 4ํ, reúne um conjunto de princípios, objetivos, instrumentos, diretrizes, metas e ações adotadas pelo governo federal, isoladamente ou em regime de cooperação com estados, distrito federal, municípios ou particulares; com vistas a atender a gestão integrada e ao gerenciamento ambientalmente adequado dos resíduos sólidos.

No mesmo ano, foi publicado o Decreto no 7.404, que além de regulamentar a Lei no 12.305/2010, cria o comitê interministerial da política nacional de resíduos sólidos, que tem como objetivo apoiar a estruturação e implementação da PNRS, por meio da articulação de órgãos governamentais, visando cumprir as determinações previstas na Lei no 12.305/2010. Cabe ressaltar que, de acordo com seu artigo quarto, compete ao comitê, dentre outras funções, formular estratégias para a promoção de tecnologias limpas para o gerenciamento de resíduos sólidos e incentivar a pesquisa e o desenvolvimento de atividades direcionadas à reciclagem, reaproveitamento e tratamento dos resíduos sólidos.

Observando o exposto acima, pode notar que a legislação pertinente à questão dos resíduos sólidos é recente, mas encontra-se em processo de evolução e aprimoramento. Ao direcionar o foco para o âmbito estadual, percebe-se que o estado do Rio de Janeiro aborda de maneira específica a questão dos resíduos sólidos. Visto que, conta com a Lei no 4.191/2003, que dispõe sobre a política estadual de resíduos sólidos (PERS), na qual são estabelecidos princípios e critérios referentes à geração acondicionamento, armazenamento, coleta, transporte, tratamento e destinação final dos resíduos sólidos no estado do Rio de Janeiro, visando controle da poluição e minimização de impactos ambientais. A PERS tem como um dos seus objetivos, estimular a implantação de novas tecnologias e processos para tratamento, reciclagem e disposição final dos resíduos sólidos.

Ainda, de acordo com a Lei no 4.191/2003, o estado do Rio de Janeiro deve incentivar estudos, projetos e programas que enfoquem problemas socioeconômicos e ambientais e deve estimular o desenvolvimento de pesquisas científicas cujo objetivo seja estudar problemas ambientais e propor o desenvolvimento de produtos, processos, modelos e sistemas de significativo interesse ambiental, econômico e social.

Já na esfera municipal, a lei orgânica do município de Macaé esclarece que compete ao município prover sobre a limpeza das vias e logradouros públicos, remoção e destino do resíduo domiciliar. Vale ressaltar que, segundo a citada lei, fica expressamente vedado no território municipal o armazenamento e a eliminação inadequada de resíduos domésticos, industriais, hospitalares, tóxicos ou de risco.

Posteriormente, foi publicada no município a Lei Complementar no 027/2001, que dispõe sobre o código municipal de meio ambiente, no qual fica instituído que o município deve implantar 
sistema adequado de coleta, tratamento e destinação dos resíduos sólidos urbanos, incluindo coleta seletiva, segregação, reciclagem, compostagem e outras técnicas que promovam a redução do volume total dos resíduos sólidos gerados. Segundo a citada lei complementar, a ação de poluir - solo por lançamento de resíduos sólidos ou líquidos encontra-se sujeita a incorrer multa de 960 (novecentos e sessenta) a 480.000 (quatrocentos e oitenta mil) unidades de referência municipal (URM's).

\subsubsection{Política Nacional de Resíduos Sólidos}

Em 02 de agosto de 2010 foi instituída a política nacional de resíduos sólidos, através da Lei Federal no 12.305 que dispõe sobre princípios, objetivos e instrumentos relativos à gestão integrada e ao gerenciamento de resíduos sólidos, às responsabilidades dos geradores e do poder público. Vale ressaltar que, estão sujeitas à observância desta lei as pessoas físicas ou jurídicas, de direito público ou privado, responsáveis direta ou indiretamente, pela geração de resíduos sólidos e as que desenvolvam ações relacionadas à gestão integrada ou ao gerenciamento de resíduos sólidos.

Os princípios da PNRS, que em linhas gerais, visam garantir uma visão sistêmica, na gestão dos resíduos sólidos, considerando as variáveis ambiental, social, cultural, econômica, tecnológica e de saúde pública; o desenvolvimento sustentável; a cooperação entre as diferentes esferas do poder público, o setor empresarial e demais segmentos da sociedade; o reconhecimento do resíduo sólido reutilizável e reciclável como um bem econômico e de valor social, gerador de trabalho e renda e promotor de cidadania; a gestão integrada de resíduos sólidos e a capacitação técnica continuada na área de resíduos sólidos.

Com a PNRS busca-se alcançar os objetivos que visam à proteção da saúde pública e da qualidade ambiental; a não geração, redução, reutilização, reciclagem e tratamento dos resíduos sólidos, bem como disposição final ambientalmente adequada dos rejeitos; estímulo à adoção de padrões sustentáveis de produção e consumo de bens e serviços; adoção, desenvolvimento e aprimoramento de tecnologias limpas como forma de minimizar impactos ambientais; regularidade, continuidade, funcionalidade e universalização da prestação dos serviços públicos de limpeza urbana e de manejo de resíduos sólidos, com adoção de mecanismos gerenciais e econômicos que assegurem a recuperação dos custos dos serviços prestados, como forma de garantir sua sustentabilidade operacional e financeira, observada a Lei $\mathrm{n} 0$ 11.445/2007.

Pode-se destacar como instrumentos da PNRS a coleta seletiva; o incentivo à criação e ao desenvolvimento de cooperativas de catadores de materiais reutilizáveis e recicláveis; a cooperação técnica e financeira entre os setores público e privado para o desenvolvimento de pesquisas de novos produtos, métodos, processos e tecnologias de gestão, reciclagem, reutilização, tratamento de resíduos e disposição final ambientalmente adequada de rejeitos; a pesquisa científica e tecnológica e a educação ambiental.

\subsection{Resíduos Sólidos}

Segundo a Associação Brasileira de Normas Técnicas (ABNT), NBR no. 10.004:2004 Resíduos Sólidos - Classificação que substitui a ABNT NBR 10004:1987, resíduos sólidos podem ser classificados como os resíduos no estado sólido e semissólido, resultantes de atividades de origem industrial, doméstica, hospitalar, comercial, agrícola, de serviços e de varrição. Enquanto que, de 
acordo com a PNRS, resíduo sólido é definido, sucintamente, como material, substância, objeto ou bem descartado resultante de atividades humanas em sociedade.

Tais atividades proporcionam uma grande variedade de tipos de resíduos, portanto, houve a necessidade de classificação e para tal, utilizaram-se critérios como o risco potencial de contaminação do meio ambiente, a natureza e a origem do resíduo. Assim, os resíduos sólidos, de acordo com a ABNT (2004), quanto aos riscos potenciais de contaminação do meio ambiente podem ser classificados em:

1* Classe I - perigosos: São aqueles que, em função de suas características intrínsecas de inflamabilidade, corrosividade, reatividade, toxicidade ou patogenicidade, apresentam riscos à saúde pública através do aumento da mortalidade ou da morbidade, ou ainda provocam efeitos adversos ao meio ambiente quando manuseados ou dispostos de forma inadequada.

2* Classe II A - não perigosos e não inertes: São os resíduos que podem apresentar características de combustibilidade, biodegradabilidade ou solubilidade, com possibilidade de acarretar riscos à saúde ou ao meio ambiente, não se enquadrando nas classificações de resíduos classe I - perigosos ou classe II B - inertes.

3* Classe II B - não perigosos e inertes: São aqueles que, por suas características intrínsecas, não oferecem riscos à saúde e ao meio ambiente, e que, quando amostrados de forma representativa e submetidos a um contato estático ou dinâmico com água destilada ou deionizada, a temperatura ambiente, conforme teste de solubilização não apresentam nenhum de seus constituintes solubilizados a concentrações superiores aos padrões de potabilidade da água, excetuando-se os padrões de aspecto, cor, turbidez e sabor.

Quanto à origem, segundo o artigo 13 da Lei no 12.305/2010, os resíduos sólidos apresentam a seguinte classificação:

1* Resíduos domiciliares: os originários de atividades domésticas em residências urbanas.

2* Resíduos de limpeza urbana: os originários da varrição, limpeza de logradouros e vias públicas e outros serviços de limpeza urbana.

3* Resíduos sólidos urbanos: os originários de atividades domésticas em residências urbanas e da varrição, limpeza de logradouros e vias públicas e outros serviços de limpeza urbana.

4* Resíduos de estabelecimentos comerciais e prestadores de serviços: os gerados nessas atividades.

5* Resíduos dos serviços públicos de saneamento básico: os gerados nessas atividades.

6* Resíduos industriais: os gerados nos processos produtivos e instalações industriais.

7* Resíduos de serviços de saúde: os gerados nos serviços de saúde.

8* Resíduos da construção civil: os gerados nas construções, reformas, reparos e demolições de obras de construção civil, como também os resultantes da preparação e escavação de terrenos para obras civis.

9* Resíduos agrossilvopastoris: os gerados nas atividades agropecuárias e silviculturais, 
incluídos os relacionados a insumos utilizados nessas atividades.

10* Resíduos de serviços de transportes: os originários de portos, aeroportos, terminais alfandegários, rodoviários e ferroviários e passagens de fronteira.

11* Resíduos de mineração: os gerados na atividade de pesquisa, extração ou beneficiamento de minérios.

O aumento na produção de resíduos teve como fator determinante o acelerado crescimento demográfico da população, aliado a maior capacidade de aquisição e consumo. Na sociedade contemporânea predomina, segundo Zacarias (2000), a produção em série e a distribuição massiva de produtos e serviços. Observa-se que a produção é crescente, fato constatado como um grave problema devido a diminuição do espaço útil disponível, ameaça direta à saúde por agentes patogênicos e danos indiretos à saúde devido ao comprometimento do ar e águas subterrâneas, segundo Fellenberg (1980).

Contudo, torna-se evidente a importância de conferir, aos resíduos sólidos, destinação e disposição ambientalmente adequadas. Vale ressaltar que, a Lei no 12.305/2010, em seu artigo 3ㅇ, define destinação final ambientalmente adequada, como sendo a destinação dos resíduos para a reutilização, reciclagem, compostagem, recuperação e aproveitamento energético e esclarece que, disposição final ambientalmente adequada é a distribuição ordenada dos rejeitos em aterros, de modo a evitar danos ou riscos à saúde pública e à segurança, bem como minimizar os impactos ambientais adversos.

Dentre as principais formas de destinação ambientalmente adequadas estão relacionadas, de acordo com o IBAM (2001), a incineração, que reduz de maneira eficaz o volume dos resíduos, tornando-o absolutamente inerte; a reciclagem e a compostagem que permitem a geração de emprego e renda, economia de energia, preservação de recursos naturais e, ainda, reduzem o quantitativo de resíduos dispostos em aterros sanitários. Vale ressaltar que, a escolha da forma de destinação deve considerar os fatores técnicos, legais e financeiros.

Após realizada a destinação ambientalmente adequada, faz-se necessário efetuar a disposição do rejeito, que, de acordo com a Lei Federal no 12.305/2010 também deve ser ambientalmente adequada. De acordo com o IBGE (2011), atualmente a solução mais adequada para a destinação final são os aterros sanitários, sendo aceitável a disposição dos resíduos em aterros controlados. Visto que, o aterro controlado é caracterizado, pela NBR 8849/1985 da ABNT, por não possuir impermeabilização de base, tratamento do chorume e queima controlada dos gases gerados e o aterro sanitário, segundo a NBR 8419/1992 da ABNT, utiliza princípios de engenharia para confinar os resíduos sólidos à menor área possível e conta com elementos de proteção ambiental, como sistema de impermeabilização de base e laterais; recobrimento diário e cobertura final; coleta e drenagem de líquidos percolados; coleta e tratamentos dos gases; drenagem superficial; tratamento de líquidos percolados e sistema de monitoramento, visando minimizar os impactos ambientais negativos.

Considerando o total de municípios brasileiros, apenas 33\% adotam uma destinação adequada para os resíduos sólidos gerados em seu território, segundo o IBGE (2011). A Pesquisa Nacional de Saneamento Básico do IBGE (2000) revelou ainda que, 50,8\% dos municípios adotam uma solução reconhecidamente inadequada como destino final dos resíduos sólidos, que são os vazadouros a céu aberto. Apesar de a Pesquisa Nacional de Saneamento Básico, realizada pelo 
IBGE em 2008, revelar que $27,7 \%$ dos municípios brasileiros adotaram a solução dos aterros sanitários, número superior aos apresentados nas pesquisas anteriores, 9,6\%, em 1989 e 22,3\%, em 2000, o país ainda tem um longo caminho a percorrer para alcançar um cenário desejável na destinação final de resíduos sólidos, segundo o IBGE (2008).

Com isso, nota-se a importância de uma correta gestão dos resíduos sólidos, que deve ser iniciada ao final do processo de produção e findada em sua disposição final ambientalmente adequada, e nesse intervalo, faz-se necessário utilizar técnicas e desenvolver ações para seu acondicionamento, transporte, sua triagem, reciclagem, valoração e reutilização.

\subsubsection{Resíduos Sólidos Urbanos}

Resíduos sólidos urbanos, de acordo com o artigo 13 da Lei Federal no 12.305/2010, são resíduos originários de atividades domésticas em residências urbanas e provenientes da varrição, limpeza de logradouros e vias públicas e outros serviços de limpeza urbana.

Os resíduos sólidos urbanos domésticos, segundo Netto (1991), são constituídos por misturas de restos de alimentos, papel, papelão, plásticos, metal, vidro, madeira, trapos, entre outros. Dentre os diferentes grupos de resíduos sólidos, os domiciliares são os mais complicados em termos de manejo, pois são constituídos por uma grande diversidade de componentes.

Essa composição varia com a localidade e com o estágio de desenvolvimento do município, visto que as características desses resíduos acompanham diretamente as modificações econômicas e as transformações tecnológicas, que influenciam o modo de vida das pessoas em um ritmo cada vez mais acelerado, principalmente em relação ao uso de embalagens, devido ao aumento no consumo de produtos industrializados, de acordo com Netto (1991) e Souza, Lima e Meirelles (2000). Vale ressaltar que, a geração dos resíduos sólidos urbanos é dependente, segundo Erthal Neto (2006), de fatores culturais, nível educacional, características de gênero e idade dos grupos populacionais; sendo que as características dos resíduos podem ser afetadas, também, pelos aspectos climáticos e sazonais, influências regionais, migrações e turismo.

Assim, devido à diversidade de componentes, a gestão dos resíduos sólidos urbanos deve incluir a separação dos resíduos na fonte e, através da coleta seletiva e da triagem dos resíduos, direcioná-los para reciclagem e compostagem. Pois, dessa forma, contribui para uma menor interferência no ambiente e na saúde pública.

\subsection{Gestão Integrada de Resíduos Sólidos}

O gerenciamento integrado de resíduos sólidos urbanos é definido pelo IBAM (2001) como sendo o envolvimento de diferentes órgãos com o propósito de realizar a coleta, o tratamento e a disposição final do lixo, levando em consideração o volume e os tipos de resíduos, as características sociais e econômicas dos cidadãos. A Lei Federal no 12.305/2010 que institui a Política Nacional de Resíduos Sólidos apresenta em seu artigo 3, inciso XI que a gestão integrada de resíduos sólidos é definida com um conjunto de ações voltadas para a busca de soluções para os resíduos sólidos, considerando as dimensões política, econômica, ambiental, cultural e social.

O gerenciamento de resíduos sólidos urbanos, segundo Castilhos Junior et. al. (2003), deve ser integrado, englobando etapas articuladas entre si, desde ações visando a não geração de resíduos até a disposição final, sendo essencial a participação do governo, iniciativa privada e 
sociedade civil organizada. De maneira geral, o gerenciamento integrado pode ser caracterizado por uma combinação de processos, procedimentos e práticas que permitem integrar de forma mais eficiente os aspectos e objetivos da qualidade, do desempenho ambiental, da segurança e saúde ocupacional e da responsabilidade social.

Vale ressaltar que, o gerenciamento integrado requer parceiros, especialmente junto às lideranças da sociedade para comporem o sistema, como também, requer a identificação de alternativas tecnológicas que visem reduzir os impactos ambientais decorrentes da geração de resíduos, atender aspirações sociais e conferir aporte econômico para sustentá-lo, de acordo com - IBAM (2001). As ações devem ser desenvolvidas de maneira articulada, incluindo a participação efetiva da comunidade, as políticas públicas do município de Macaé e a sensibilização para a questão dos resíduos sólidos por meio da educação promovida pelo IFFluminense - Campus Macaé, convergindo assim, para sustentabilidade ambiental e social.

\subsubsection{Centro de Triagem e Compostagem}

Nas unidades de triagem e compostagem realiza-se a separação dos resíduos potencialmente recicláveis, resíduos orgânicos e rejeitos. Os materiais recicláveis, depois de separados, são prensados, enfardados e armazenados para posterior comercialização; a matéria orgânica é encaminhada ao pátio de compostagem e o produto final é um composto orgânico que pode ser utilizado em paisagismo, na recuperação de áreas degradadas, entre outros (FEAM, 2006) e o rejeito deve ser disposto em aterro controlado ou aterro sanitário.

Um centro de triagem e compostagem, de acordo com Pontes e Cardoso (2006), funciona como uma etapa intermediária no manejo dos resíduos sólidos e permite controlar a poluição e, ainda, conservar e recuperar recursos naturais e energéticos, principalmente a partir da reutilização de produtos recicláveis, como matéria prima, pelas indústrias. Mas, a eficiência das operações está diretamente ligada à competência e boa vontade dos funcionários, o que torna o processo vulnerável, de acordo com Grimberg e Blauth (1998), condição possível de ser superada com capacitação, oferta de condições dignas de trabalho e a partir da distribuição de renda.

Tal superação pode ser constatada a partir de iniciativas desenvolvidas nas diferentes regiões do Brasil, como no município de Florestal-MG, onde foi fundada, no ano de 2007, a associação Astriflores, cujo objetivo é auxiliar no trabalho de triagem dos resíduos gerados no município, atualmente, a associação recebe em torno de 86 toneladas de resíduos por mês, desse total, cerca de, 23 toneladas de resíduos recicláveis são vendidos, proporcionando um ganho de, aproximadamente, $\mathrm{R} \$ 9.000,00$ por mês, distribuídos entre os associados, que possuem uma renda média mensal de $\mathrm{R} \$ 784,00$, segundo Coelho et. al. (2013).

Já o estado do Paraná, apresenta um histórico de gestão de resíduos sólidos que atesta a viabilidade da implementação de projetos de reciclagem e compostagem. Como pode ser observado no município de Tibagi, que através do programa Recicla Tibagi, alcançou a meta de destinar $100 \%$ do resíduo sólido domiciliar gerado no município para o centro de triagem e compostagem, onde é realizada, pela Associação de Catadores de Materiais Recicláveis de Tibagi, a triagem dos resíduos recicláveis e a compostagem dos resíduos orgânicos, que representa $56 \%$ dos resíduos domiciliares, de acordo com Tibagi (2012). Também merece destaque no estado a rede de catadores voltada para a logística reversa, a Rede Carta Paraná, de acordo com Miecoanski (2012), as cooperativas inseridas nessa rede garantem um lucro de $20 \%$ a $30 \%$ maior e os 
cooperados ganham, em média, R\$ 700,00 por mês, além da contribuição ao Instituto Nacional do Seguro Social (INSS), garantia que o catador que não é cooperado não dispõe.

\subsubsection{Cooperativa de Catadores: Uma Alternativa Socioeconômica}

Cooperativa é definida pela Organização das Cooperativas Brasileiras (OCB) como sendo uma sociedade de pessoas físicas, unidas pela cooperação e ajuda mútua, gerida de forma democrática e participativa, com objetivos econômicos e sociais comuns. A fundamentação básica para a organização de uma cooperativa é o intuito de melhorar as condições econômicas dos cooperados, uma vez que passam a inserir produtos e serviços no mercado, em condições mais vantajosas do que eles teriam isoladamente (SEBRAE, 2014).

No Brasil, as cooperativas são regulamentadas na Constituição Federal, no Novo Código Civil e, também, pela Lei Federal no 5.764/1971, conhecida como Lei do Cooperativismo. Nessa legislação vigente estão descritas as principais regras que regem o modelo cooperativista e que embasam sua organização. No estado do Rio de Janeiro, as cooperativas alcançaram uma conquista com a publicação da Resolução CONEMA no 56/2013, que estabelece critérios para a inexigibilidade de licenciamento ambiental para associações e cooperativas que desenvolvem atividades de recebimento, prensagem, enfardamento e armazenamento temporário de resíduos sólidos recicláveis não perigosos, inertes e oriundos de coleta seletiva.

Em geral, as cooperativas que alcançam melhores resultados são, segundo Freitas e Fonseca (2011), aquelas apoiadas pelo poder público das diferentes esferas, por entidades da sociedade civil ou órgãos não governamentais. Entretanto, para alcançar o sucesso, é preciso que a cooperativa cumpra, segundo Lelis e Pereira Neto (2001), um item de fundamental importância, que é a qualificação da mão de obra, apesar da triagem e da compostagem serem consideradas operações simples, torna-se indispensável à preparação e treinamento das pessoas que atuarão no sistema.

Nos diferentes estados brasileiros são encontrados exemplos que evidenciam a importância da participação de cooperativas na gestão integrada de resíduos sólidos. Em Belo Horizonte, estado de Minas Gerais, a Associação dos Catadores de Papel, Papelão e Material Reaproveitável (ASMARE) merece destaque, devido à realização de um trabalho que contribui significamente para a melhoria do meio ambiente, geração de trabalho e renda e, ainda, proporciona uma verdadeira cadeia de responsabilidade social. A ASMARE, segundo Guazina e Belizario (2012), atualmente possui 286 associados, responsáveis pela coleta, triagem, prensagem e comercialização de 421 toneladas de resíduos recicláveis, a partir do qual obtém uma renda média mensal de $\mathrm{R} \$ 550,00$, renda que permitiu, ao longo dos anos de trabalho, $97 \%$ dos associados conquistarem a casa própria, conforme explica Gonçalves, Oliveira e Silva (2008).

Vale ressaltar que, a cooperativa tende a propiciar, segundo Abreu (2001) e Arcanjo e Marques (2012), a oportunidade de resgatar a autoestima do trabalhador através do trabalho solidário, proporcionando sua inclusão na sociedade como profissionais e cidadãos. Assim, em um sentido mais amplo, o centro didático-pedagógico pode propiciar inclusão social, conferindo ao cidadão a oportunidade de acesso à educação, a partir da participação em cursos de capacitação e treinamentos. 


\subsubsection{Educação Ambiental no Contexto do Gerenciamento Integrado de Resíduos Sólidos}

A Educação Ambiental pode ser considerada como parte de um processo permanente, no qual os indivíduos adquirem conhecimentos, valores, habilidades e experiências que os tornem aptos a agir e resolver a problemas ambientais presentes e futuros (UNESCO, 1987). De acordo com Ab'Saber (1991), a educação ambiental envolve um vigoroso esforço de recuperação de realidades, destinada a reformular comportamentos humanos. Segundo Dias (1992), a educação ambiental deve ser um processo contínuo, interdisciplinar e dirigido a toda a sociedade, vinculado à legislação e às políticas ambientais.

A educação ambiental pode contribuir efetivamente para renovar o processo de ensino, uma vez que constitui a base para a transformação crítica dos sistemas educativos, podendo alcançar uma mudança comportamental na população, e consequentemente, uma sociedade sustentável. Segundo Reigota (1998) a escola tem sido historicamente, o espaço indicado para a discussão e o aprendizado de vários temas urgentes da atualidade, devido a sua importância na formação dos cidadãos.

Dentre as estratégias da educação ambiental direcionadas para a sensibilização com relação aos resíduos sólidos pode-se destacar, segundo Bassani (2011), IPEA (2012) e Meira (s/d), a de reprodução de vídeos sobre resíduos sólidos; realização de palestras; campanhas pontuais de coleta de materiais recicláveis; oficinas sobre consumo sustentável e encontros educativos, visando sensibilizar o indivíduo sobre a problemática socioambiental e sobre a necessidade de conservação de recursos naturais. Confirmando o estabelecido no Decreto Federal no 7.404/2010, onde consta que devem ser incentivadas as atividades de caráter educativo e pedagógico.

Neste cenário, o centro didádico-pedagógico deve constituir a base para a educação ambiental, cujo objetivo é incutir na comunidade escolar a necessidade e urgência de preservar o ambiente e, também, instruir a população envolvida como proceder a segregação e acondicionamento dos resíduos, conferindo sentido e relevância para a efetiva mudança comportamental na sociedade.

\subsubsection{Panorama Atual do Gerenciamento de Resíduos Sólidos no Município de Macaé}

Localizado no estado do Rio de Janeiro, o município de Macaé, de acordo com dados do IBGE (2010), possui extensão territorial de $1.216 \mathrm{~km}^{2}$ e índice de desenvolvimento humano municipal na ordem de 0,764. O município de Macaé merece destaque na economia nortefluminense, visto que, em 1974 foi descoberto um amplo lençol petrolífero no campo de Garoupa e a cidade de Macaé passou a ser conhecida como a capital nacional do petróleo, fato que contribuiu para o aumento populacional e, consequentemente, para a expansão desordenada, de acordo com Macaé (2012), ocasionando problemas de ordem social, econômica e ambiental.

Atualmente, a Secretaria Municipal de Limpeza Pública (SELIMP) é o órgão da administração pública responsável pela coordenação da coleta de resíduos no município de Macaé, segundo Macaé (2012). Mas, a execução da coleta, que atende $100 \%$ da população urbana, é realizada por uma empresa privada contratada pela Prefeitura Municipal de Macaé, tal contrato inclui, além da coleta, o transporte até a disposição final, no aterro sanitário, de acordo com a SNSA (2013). A coleta do resíduo domiciliar, de acordo com Macaé (2012), é realizada diariamente e em dias alternados. Segundo SNSA (2013), 10\% da população urbana é atendida com uma 
frequência diária e 90\% com uma frequência de 2 ou 3 vezes por semana. O serviço conta com 15 caminhões compactadores que, executam rotas diurnas e noturnas, efetuando a coleta domiciliar porta a porta em todas as vias públicas oficiais da sede municipal, conforme descrito por Macaé (2012).

Após a coleta, de acordo com Macaé (2012), os resíduos são destinados à Central de Tratamento de Resíduos (CTR), à margem direita da BR101 sentido Campos-Rio de Janeiro, entre os Km 148 e Km 149, distante, cerca de, 25 km do centro do município de Macaé, onde localiza-se, também, o aterro sanitário, que entrou em operação no ano de 2009 e, atualmente, funciona, diariamente, 24 horas para recebimento dos resíduos coletados e é operacionalizado por um empresa privada, que possui um contrato de prestação de serviços com a Prefeitura de Macaé. Ao entrar no CTR, o caminhão é estacionado na balança, a fim de verificar a pesagem do caminhão com os resíduos e, após efetuar a descarga, é pesado novamente, com o objetivo de obter apenas o peso do caminhão, segundo informações de Macaé (2012), assim, com uma simples operação matemática, pode-se obter o peso dos resíduos coletados.

No município de Macaé, segundo informações, da SNSA (2013), com uma população urbana de 208.457 habitantes, foram coletadas, no ano de 2011, 81.640 toneladas de resíduo domiciliar, mas, vale ressaltar que, a prefeitura não possui dados referentes ao quantitativo de resíduos coletados por catadores. Portanto, com base nos dados referenciados acima, estima-se que, no município de Macaé, sejam coletadas, em média, 6.803 toneladas de resíduos por mês, correspondendo, aproximadamente, a 223,7 toneladas por dia, considerando que, de acordo com Monteiro (2001), em cidades médias e pequenas, com menos de 500 mil habitantes, a geração de resíduos gira, em torno de, 0,55 quilos de resíduos por habitante a cada dia; o município de Macaé encontra-se fora desse referencial, visto que, apresenta uma geração, aproximada, de 1,08 quilos de resíduos por habitante a cada dia.

\section{METODOLOGIA}

O campus Macaé do IFFluminense localiza-se às margens da Lagoa de Imboassica, no município de Macaé, estado do Rio de Janeiro e a definição da área de estudo teve como critério a proximidade com o Instituto (como demonstrado na Figura 1), objetivando facilitar a logística de transporte dos resíduos e a redução de custos. Portanto, abrange os bairros Jardim Guanabara e Mirante da Lagoa e os condomínios residenciais Vale dos Cristais, Green Land, Golden Sun, Garden Hill e dos Ipês, todos localizados no entorno do IFFluminense - Campus Macaé.

Para melhor contextualização do lugar apresenta-se na Figura 1, a área em verde, denominada Vale dos Cristais que abrange os condomínios residenciais Vale dos Cristais, Green Land, Golden Sun e Garden Hill; a área em amarelo que compreende o bairro Jardim Guanabara e o condomínio residencial dos Ipês e a área em azul o bairro Mirante da Lagoa. 
Carta Imagem - IFFluminense - Macaé: Centro Didático Pedagógico Para Gerenciamento de Resíduos
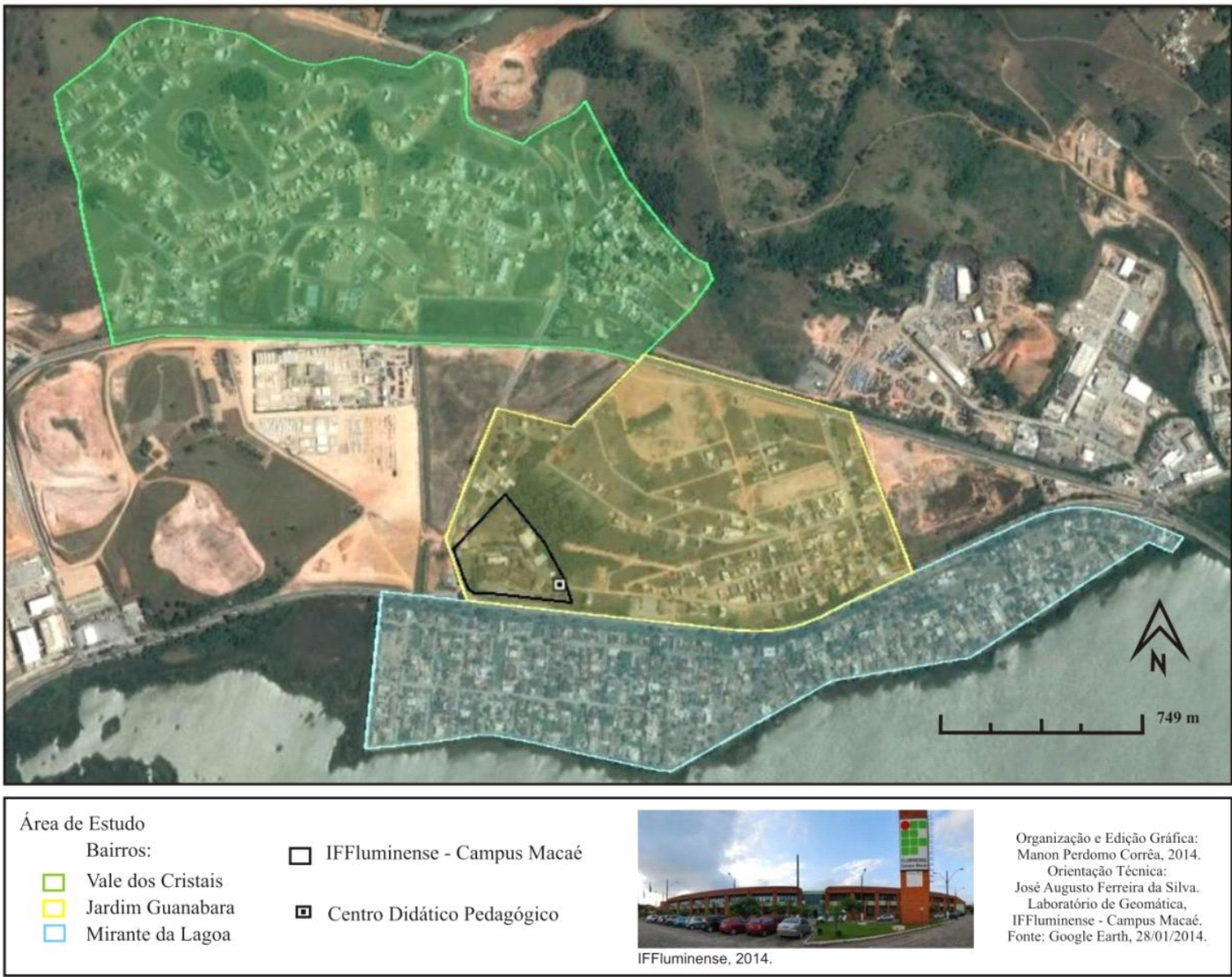

Figura 1 - Localização do centro didático-pedagógico e da área de estudo.

Os bairros e os condomínios residenciais estão localizados no setor administrativo 01 - azul, segundo a Lei Complementar no 045/2004, que dispõem sobre a divisão administrativa do município e promove novo ordenamento territorial. Os Setores Administrativos constituem-se em unidades integrantes do sistema de planejamento e administração, de acordo com o Art. 31 da Lei Complementar no 045/2004.

O setor administrativo 01 - azul, como afirma Silva e Nogueira (2012), é considerado um setor nobre, onde há uma acentuada valorização imobiliária e uma alta concentração de renda salarial; fato que reafirma a análise do desenvolvimento socioeconômico do município de Macaé, realizada por Costa (2005) e coincide com o estudo realizado por Silva e Faria (s/d), que afirma a ocorrência de renda salarial elevada em todos os bairros componentes do o setor; população com alto nível de escolaridade e com empregos ligados diretamente ao setor petrolífero. De acordo com o IBGE (2010), o setor possui 9.071 domicílios e $98,54 \%$ dos resíduos gerados possuem destinação regular. Entretanto, alguns bairros ainda não contam com o serviço de esgotamento sanitário, este fato pode estar atrelado ao rápido crescimento do setor, segundo Macaé (2010).

Para o desenvolvimento do presente trabalho, utilizou-se o método empírico, que considera a experiência comum. Em âmbito mais específico, pode ser classificado como um método fenomenológico, que, segundo Giorgi (1985), começa com uma descrição, uma situação vivida no cotidiano. Contudo, visando subsidiar o estudo de viabilidade do centro didáticopedagógico, foram realizadas entrevistas qualificadas com representantes do IFFluminense - 
Campus Macaé, da Prefeitura Municipal de Macaé e da sociedade civil, objetivando registrar a realidade cotidiana e obter informações sobre a temática resíduos sólidos; importância das cooperativas e atuação das mesmas no município de Macaé; relevância da educação ambiental como base para uma mudança comportamental e sensibilização da população; o desenvolvimento de políticas públicas e investimentos direcionados ao setor de resíduos sólidos. Permitindo assim, consolidar a discussão fundamentada sobre a temática e compor o panorama atual do gerenciamento de resíduos sólidos urbanos no município de Macaé.

\section{RESULTADOS E DISCUSSÕES}

No município de Macaé as informações sobre resíduos sólidos são desencontradas e alguns dados apresentam inconsistências, como pode ser observado na situação atual da coleta seletiva, pois o Plano Municipal de Resíduos Sólidos de Macaé informa que é realizada a Coleta Seletiva em Vivendas da Lagoa e Mirante da Lagoa, segundo Macaé (2012); enquanto que, Macaé (2014) informa que a coleta seletiva é realizada nos bairros Mirante da Lagoa, Praia do Pecado e nas escolas. Entretanto, observando os dados do Sistema Nacional de Informações sobre Saneamento (SNIS), cujas informações são cedidas pelo município, consta que o município de Macaé não conta com o sistema de coleta seletiva, de acordo com SNSA (2013). Sabe-se que Macaé possui um caminhão compactador que utiliza adesivos da coleta seletiva, mas o município não efetua a triagem dos resíduos coletados, segundo SNSA (2013), portanto, todo resíduo coletado é enviado para o aterro sanitário.

Considerando que o município de Macaé efetua a cobrança pelo serviço de coleta de resíduos, prevista na Lei Complementar no 053/2005, que institui o Código Tributário do Município de Macaé - RJ, torna-se evidente a necessidade de investir e atualizar o planejamento e o gerenciamento dos resíduos a fim de obter uma melhoria ambiental, econômica e social. Assim, o centro didático-pedagógico, em escala piloto, pode ser utilizado como modelo para que a gestão pública do município de Macaé inicie o gerenciamento em outros bairros do município, diminuindo assim, os custos com a disposição final dos resíduos no aterro sanitário.

De acordo com estudo realizado no município de Macaé por Dias (2011), a implantação de uma usina de reciclagem e compostagem mostra-se como opção viável, não só do ponto de vista econômico, mas também do ambiental, pois a carga orgânica tem uma contribuição muito alta no percentual total dos resíduos do município, em torno de $36 \%$, e o não reaproveitamento deste material contribui para a diminuição da vida útil do aterro sanitário.

Assim, nota-se a importância do centro didático-pedagógico no gerenciamento dos resíduos sólidos, não só para o IFFluminense - Campus Macaé, como também para o município de Macaé. Entretanto, faze-se necessário avaliar se o quantitativo de resíduos gerados no IFFluminense - Campus Macaé; nos bairros Jardim Guanabara e Mirante da Lagoa e nos condomínios residenciais Vale dos Cristais, Green Land, Golden Sun, Garden Hill e dos Ipês é suficiente para gerar uma renda digna aos cooperados.

\section{CONCLUSÃO}

No Brasil, ainda há desinformação acerca das alternativas para a destinação dos resíduos sólidos, conforme ressalta Lelis e Pereira Neto (2001), a opção pelos sistemas de triagem e 
compostagem deve ser precedida de um diagnóstico, objetivando avaliar todas as informações necessárias para subsidiar a tomada de decisão sobre a viabilidade técnica e econômica do sistema. Entretanto, a gestão adequada dos resíduos sólidos no Brasil deve ser efetivada com a máxima urgência, devido ao desencadeamento de ações públicas desarticuladas que, além de impedirem o equacionamento dos problemas, geram desperdícios significativos na aplicação de recursos públicos (Schalch et. al., 2002).

Pelo sucesso alcançado por diversos sistemas, seguindo a concepção de Lelis e Pereira Neto (2001) nota-se a viabilidade da adoção de processos de triagem como alternativa para o tratamento dos resíduos sólidos urbanos, tendo em vista a real possibilidade de reintrodução, no processo produtivo, dos materiais recicláveis, proporcionando melhorias para a economia e estimula a participação da sociedade no exercício de sua cidadania.

Em paralelo à implantação do sistema de triagem dos resíduos sólidos faz-se necessário, segundo Lelis e Pereira Neto (2001), a realização de um trabalho de mobilização comunitária, fundamental para o sucesso do sistema, de maneira a obter melhoria nas condições sanitárias e ambientais e proporcionar a difusão de conhecimento a partir da educação ambiental.

Em síntese é possível inferir que a gestão integrada de resíduos sólidos, a partir da implantação do centro didático-pedagógico tende a promover a inclusão social, através da cooperativa, bem como benefícios econômicos e melhoria nas condições ambientais, não só para o IFFluminense - Campus Macaé, como também para o município de Macaé.

\section{REFERÊNCIAS BIBLIOGRÁFICAS}

1. ABNT. Associação Brasileira de Normas Técnicas. NBR - 8849: Apresentação de projetos de aterros controlados de resíduos sólidos. 1985.

2. _ NBR - 8419: Apresentação de projetos de aterros sanitários de resíduos sólidos urbanos. 1992.

3. _ N N NBR - 10.004: Resíduos sólidos - classificação. 2004.

4. $A B^{\prime} S A B E R, A$. N. (Re) conceituando educação ambiental. Rio de Janeiro, 1991.

5. ABREU, M. F. Do lixo a cidadania: estratégia para a ação. São Paulo. UNICEF/Caixa Econômica Federal, 2001.

6. ARCANJO, R. S. \& MARQUES, J. B. O cooperativismo popular na perspectiva da economia solidária como instrumento de inclusão social produtiva. IX Simpósio de Excelência em Gestão e tecnologia. Resende/RJ, 2012.

7. BASSANI, F. Práticas de educação ambiental voltadas aos resíduos sólidos de uma unidade escolar de Conceição do Araguaia-Pará. Il Congresso Brasileiro de Gestão Ambiental, Londrina, 2011.

8. BRASIL. Lei $\mathrm{n}$ - 9.605, de 12 de fevereiro de 1998. Dispões sobre as sanções penais e administrativas derivadas de condutas e atividades lesivas ao meio ambiente e dá outras providências. Disponível em: <http://www.planalto.gov.br/ccivil_03/leis/19605.htm>. Acesso em 20/06/2014.

9.

Lei $\mathrm{n}$ - 11.445, de 5 de janeiro de 2007. Estabelece diretrizes nacionais para o saneamento básico; altera as Leis no 6.766, de 19 de dezembro de 1979, 8.036, de 11 de maio 
de 1990, 8.666, de 21 de junho de 1993, 8.987, de 13 de fevereiro de 1995; revoga a Lei no 6.528, de 11 de maio de 1978 e dá outras providências. Disponível em: <http://www.planalto.gov.br/ccivil_03/_ato2007-2010/2007/lei/l11445.htm>. Acesso em 20/06/2014.

10.

Decreto no 7.217, de 21 de junho de 2010. Regulamenta a Lei no 11.445, de 5 de janeiro de 2007, que estabelece diretrizes nacionais para o saneamento básico, e dá outras providências. Disponível em: <http://www.planalto.gov.br/ccivil_03/_ato20072010/2010/Decreto/D7217.htm>. Acesso em: 20/06/2014.

11. . Lei no 12.305, de 02 de agosto de 2010. Institui a política nacional de resíduos sólidos; altera a Lei no. 9.605, de 12 de fevereiro de 1998 e dá outras providências. Disponível em: <http://www.planalto.gov.br/ccivil_03/_ato2007-2010/2010/lei/l12305.htm>. Acesso em 12/09/2013.

12. Decreto № 7.404, de 23 de dezembro de 2010. Regulamenta a Lei $n=12.305$, de 2 de agosto de 2010, que institui a Política Nacional de Resíduos Sólidos, cria o Comitê Interministerial da Política Nacional de Resíduos Sólidos e o Comitê Orientador para a Implantação dos Sistemas de Logística Reversa e dá outras providências. Disponível em: <http://www.planalto.gov.br/ccivil_03/_ato2007-2010/2010/Decreto/D7404.htm>. Acesso em: 19/06/2014.

13. CASTILHOS JUNIOR, A. B. et. al. Resíduos sólidos urbanos: aterro sustentável para municípios de pequeno porte. Rio de Janeiro: ABES/RIMA. 2003.

14. CEN. Y. Características das inovações no setor de gestão de resíduos e o padrão distinto do uso da incineração de resíduos na China. In: STRAUCH, M.; ALBUQUERQUE, P. União Protetora de Ambiente Natural. Resíduos: como lidar com recursos naturais. São Leopoldo, RS: Olkos, UPAN, p. 105-143, 2008.

15. COELHO, J. W. O. et. al. Aspectos das condições estruturais e de funcionamento da unidade de triagem, Astriflores da cidade de Florestal, Minas Gerais. IV Congresso Brasileiro de Gestão Ambiental, Salvador-BA, 2013.

16. CONEMA. Conselho Estadual de Meio Ambiente. Resolução no 56 de 13 de dezembro de 2013. Estabelece critérios para a inexigibilidade de licenciamento ambiental para associações e cooperativas de catadores para atividade de recebimento, prensagem, enfardamento e armazenamento temporário de resíduos sólidos recicláveis não perigosos, inertes e oriundos de coleta seletiva. Disponível em: <http://www.rj.gov.br/web/sea/exibeConteudo?articleid=162754 >. Acesso em: 15/07/2014.

17. DIAS, G. F. Educação ambiental: princípios e práticas. Gaya, 1992.

18. DIAS, M. V. Viabilidade de implantação de uma usina de triagem e compostagem de lixo no município de Macaé. Dissertação de Mestrado, IFFluminense, Macaé, 2011.

19. ERTHAL NETO, E. L. Destinação final dos resíduos sólidos urbanos no estado do Rio de Janeiro e a aplicação dos instrumentos de regulamentação e controle ambiental: uma abordagem crítica. Dissertação de Mestrado, Fundação Oswaldo Cruz, Rio de Janeiro, 2006.

20. FEAM. Fundação Estadual do Meio Ambiente. Orientações básicas para a operação de aterro sanitário. Belo Horizonte, 2006.

21. FELLENBERG, G. Introdução aos problemas da poluição ambiental. São Paulo: EPUSP, 1980. 
22. FERREIRA, J. A. Resíduos Sólidos: perspectivas atuais. In: SISINNO, C. L. S.; OLIVEIRA, R. M. de (Org.). Resíduos sólidos, ambiente e saúde: uma visão multidisciplinar. Rio de Janeiro: Ed. FIOCRUZ, p. 19-40. 2000.

23. FREITAS, L. F. S. \& FONSECA, I. F. Caderno de diagnóstico - catadores. IPEA, 2011.

24. GIORGI, A. O. Phenomenological and psychological research. Pittsburgz: Ducherne University Press, 1985.

25. GONÇALVES, J. A., OLIVEIRA, F. G. \& SILVA, D. T. A. Dezoito anos catando papel em Belo Horizonte. Estudos Avançados n²2, 2008.

26. GRIMBERG, E \& BLAUTH, P. Coleta seletiva ou usina de reciclagem e compostagem?. Livro: Coleta Seletiva - Reciclando Materiais, Reciclando Valores. Instituto Pólis, São Paulo, 1998. Disponível em: < http://www.lixo.com.br/content/view/145/253/>. Acesso em: 17/07/2014.

27. GUAZINA, L.; BELISÁRIO, K. M. Repensando o planejamento em tempos de globalização e transformações sociais. Esferas, $n^{\circ}$ 1, 2012.

28. IBAM. Instituto Brasileiro de Administração Municipal. Manual de gerenciamento integrado de resíduos sólidos. MONTEIRO, J. H. P. et. al.; coordenação técnica Zveibil, V. Z. Rio de Janeiro, 2001.

29. IBGE. Instituto Brasileiro de Geografia e Estatística. Pesquisa nacional de saneamento básico. 2000. Disponível em: <http://www.ibge.gov.br>. Acesso em: 12/11/2013.

30. _. Pesquisa nacional de saneamento básico. 2008. Disponível em: <http://www.ibge. gov.br>. Acesso em: 19/06/2014.

31. Censo demográfico 2010. 2010. Disponível em: <http://www.ibge.gov.br>. Acesso em $18 / 07 / 2014$.

32. __ Atlas de saneamento 2011. 2011. Disponível em: <http://www.ibge.gov.br >. Acesso em 02/10/2013.

33. IPEA. Instituto de Pesquisa Econômica Aplicada. Diagnóstico de educação ambiental em resíduos sólidos. Relatório de Pesquisa. Brasília, 2012.

34. LELIS, M. P. N. \& PEREIRA NETO, J. T. Usinas de reciclagem de lixo: porque não funcionam?. 210 Congresso Brasileiro de Engenharia Sanitária e Ambiental. Trabalhos Técnicos, João Pessoa, 2001.

35. LICHTNOW, J. C.; POZZOBON, M. G. G \& FOIATO, V. F. Gestão dos resíduos sólidos urbanos do município de Diamante do Oeste - Paraná. Monografia. ISEPE, Marechal Cândido Rondon, 2004.

36. MACAÉ. Lei orgânica do município de Macaé. Disponível em: <http://www.macae.rj.gov.br/mi dia/conteudo/arquivos/1322671708.pdf>. Acesso em: 19/06/2014.

37. L_ Lei complementar no 027, de 26 de dezembro de 2001. Dispõe sobre o código municipal de meio ambiente e dá outras providências. Disponível em: <http://www.ma cae.rj.gov.br/midia/conteudo/arquivos/1354927959.pdf>. Acesso em: 19/06/2014.

38. L__ Lei complementar no. 053/2005. Institui o código tributário do município de Macaé RJ. Disponível em: < http://www.macae.rj.gov.br/midia/conteudo/arquivos/12810036 51.pdf>. Acesso em: 19/07/2014. 
39. MARTINS J. \& BICUDO M. A. A pesquisa qualitativa em psicologia: fundamentos e recursos básicos. São Paulo: Moraes, 1989.

40. MEIRA, A. M. et. al. Articulando educação ambiental, resíduos sólidos e sustentabilidade: estratégias e desafios no contexto universitário. Programa USP Recicla. USP, São Paulo, s/d. Disponível em: <http://www.ealusofono.org/comunicacions/EA_e_Universidade/Meira_Ana Mariade.html>. Acesso em 19/07/2014.

41. MIECOANSKI, E. Paraná começa a desenvolver redes para melhorar a vida dos catadores de lixo. 2012. Disponível em: <http://www.gazetadopovo.com.br/vidaecidadania/conteudo. phtml ?id=1243342>. Acesso em: 17/07/2014.

42. MONTEIRO, J. H. P., Pesquisa nacional de saneamento básico - PNSB 2000: limpeza urbana e coleta de lixo. Rio de Janeiro, 2001.

43. NETTO, J. M. Manual de saneamento de cidades e edificações. PINI, São Paulo, 1991.

44. OCB. Organização das Cooperativas Brasileiras. Disponível em < http://www.ocb.org.br/site/ brasil_cooperativo/index.asp>. Acesso em 28/10/2013.

45. PONTES, J. R. M. \& CARDOSO, P. A. Usina de reciclagem e compostagem de lixo em Vila Velha: viabilidade econômica e a incorporação de benefícios sociais e ambientais. ABEPRO. XXVI ENEGEP Fortaleza, 2006.

46. REIGOTA, M. Desafios à educação ambiental escolar. In: CASINO, F; JACOBI, P; OLIVEIRA, J. Educação, meio ambiente e cidadania: reflexões e experiências. São Paulo, Secretaria do Meio Ambiente, 1998.

47. RIO DE JANEIRO. Lei no 4.191, de 30 de setembro de 2003. Dispões sobre a política estadual de resíduos sólidos e dá outras providências. Disponível em: <http://alerjln1.alerj.ri.gov. br/CONTLEI.NSF/c8aa0900025feef6032564ec0060dfff/cf0ea9e43f8af64e83256db300647e83 ?OpenDocument\&Highlight=0,Lei,4191>. Acesso em: 19/06/2014.

48. SCHALCH, V. et. al. Gestão e gerenciamento de resíduos sólidos. USP, São Carlos, 2002.

49. SEBRAE. Serviço Brasileiro de Apoio às Micro e Pequenas Empresas. Cooperativa. Série Empreendimentos Coletivos. Brasília, 2014. Disponível em: <http://bis.sebrae.com.br/Gestor Repositorio/ARQUIVOS_CHRONUS/bds/bds.nsf/CF527A837A1B4E2F8325766A0052780D/\$Fil e/NT00042C2E.pdf>. Acesso em: 20/05/2014.

50. SNSA. Secretaria Nacional de Saneamento Ambiental. Sistema nacional de informações sobre saneamento - SNIS: diagnóstico do manejo de resíduos sólidos urbanos - 2011. Ministério das Cidades, Brasília, 2013.

51. SOUZA, E.; LIMA, C. \& MEIRELLES, S. I. Reciclagem de entulho. CPT, Viçosa, 2000.

52. TIBAGI. Prefeitura Municipal de Tibagi. Apresentação Recicla Tibagi. In: Revitalização das Promotorias Ambientais por Bacias Hidrográficas, Curitiba, 2012.

53. UNESCO. Organização das Nações Unidas para a Educação, a Ciência e a Cultura. Educação ambiental, situação espanhola e estratégia internacional. In: Congresso Internacional UNESCO/PNUMA sobre La Educacion y La Formacion Ambientales, Moscou: DGMA-MOPU, 1987.

54. ZACARIAS, R. Consumo, lixo e educação ambiental. Juiz de Fora: Ed. FEME, 2000. 